\title{
Towards primary care groups The development of local healthcare cooperatives in Scotland
}

\author{
Jane Hopton, David Heaney
}

The plan for the NHS in Scotland mapped out in the white paper Designed to Care 1 shares common values and goals with the plans for England and Wales. The organisational structures proposed to underpin Scotland's strategy for the health service (box) are, however, substantively different from those proposed for England and Wales.

Primary care trusts are new statutory organisations scheduled to go live in April 1999. Participation in local healthcare cooperatives (LHCCs) is voluntary. Designed to Care specified that primary care trusts will be funded by health boards and will include community health services, all mental health services, services for people with disabilities, and continuing care of elderly people as well primary care services based in general practice. There will no longer be commissioning in Scotland. Service development will be based on collaborative strategic planning between trusts and health boards.

The abandonment of commissioning has left continuing uncertainty about general practitioners' public health and strategic roles. Designed to Care recommended, but did not insist, that general practitioners should form new bodies called local healthcare cooperatives but gave no detailed vision of cooperatives' role, function, or structure. Until recently the Scottish Office has deliberately kept central guidance to the minimum on the grounds that there should be opportunity to allow diversity in response to local circumstances; that collaborative working among general practitioner practices is at different stages of evolution in different parts of the country; and that it was inappropriate for detailed decisions on local structures to be taken until the primary care trusts could be involved. Recent planning guidance concentrated on the role of primary care trusts, but offered a vision for local healthcare cooperatives as "clinically led networks focused on improving services, quality, and standards" and "supported by the primary care trust."

The reconfiguration of existing trusts brought major change throughout the system, to be implemented within a short timescale. From the perspective of the Scottish Office, "A key issue has been to keep various parts of the system in step." The NHS Management Executive explained that although it recognised that general practitioners wanted to grasp the opportunities offered, "in practice the primary care trusts of which local healthcare cooperatives are a part have to be involved in discussions."

This report focuses on the development of two contrasting local healthcare cooperatives within Lothian's new primary care trust.

\section{The NHS in Lothian}

Lothian has a history of developing cooperative working among general practices based on seven geographical areas or localities. Each locality had a small team of gen-

\section{Summary points \\ In Scotland, partnership and planning are replacing commissioning, and primary care trusts are being introduced immediately \\ Local healthcare cooperatives will be part of the of four articles showing how primary care groups have been set up in various areas in Britain} new primary care trusts

In Lothian health board area, the cooperatives have been developed from existing locality planning structures and led by a Lothian-wide multidisciplinary steering group prior to the new trusts being in place

Two cooperatives within Lothian's new primary care trust differ considerably: one is developing the structure of a management organisation, another is evolving into a clinical network

The scale of organisational change in Scotland has been considerable, and several fundamental areas of uncertainty remain

This is the third

Department of General Practice, University of Edinburgh, Edinburgh EH8 9DX Jane Hopton, research psychologist David Heaney, research fellow

Correspondence to: Ms Hopton jlh@ srv1.med.ed.ac.uk

Series editor: Trish Groves

BMJ 1999;318:1185-7

eral practitioners with one leader, a half time locality development manager, and central administrative support. This structure has provided the transitional basis for developing local healthcare cooperatives.

Reaction from primary care professionals to the reforms was mixed. Some felt positive about the overall strategy, others that it had potential. Most, however, were surprised and disappointed at the big differences between Scotland's plans and those for England and Wales, where commissioning will be led by primary care. General practitioners were particularly worried about managing prescribing budgets within primary care in isolation from resources in the acute secondary sector.

There was a consensus among Lothian Health, the existing trusts, and professional advisory bodies that local healthcare cooperatives should be strong organisations with maximum devolved power and responsibility, with primary care trusts as federal organisations facilitating and supporting its constituent cooperatives.

To develop the "bottom up," collective approach that had already shaped the general practice based locality groups, Lothian has set up a multidisciplinary local healthcare cooperative steering group to act as a "virtual primary care trust." As its chair, Cindy Brook, explained, its functions have been to coordinate the development of the cooperatives across the region and to manage the "big negative morale issue about the gap between the top and the bottom."

The steering group is ensuring that cooperatives work with a wide range of disciplines including patient 


\section{Key features of the organisational structure for the NHS in} Scotland

\section{Overall strategy:}

Emphasis on the NHS in Scotland as a single organisation

Immediate reduction in the number of trusts; most health boards to have one primary care and one acute trust

End of contracting and commissioning and the development of partnership and planning*

Development of the joint investment fund $\dagger$ as a means of managing the interface between primary and secondary care

\section{Primary care trusts:}

In place as new organisations from April 1999

The legal entity, directly accountable to the health board

Include general community services, services for priority groups including older people, and people with disabilities; mental health services; and general practices

Local negotiation on placing of other services in acute or primary care trust Include local health cooperatives based on general practices

\section{Local health cooperatives:}

Not legal entities

Not commissioning acute services

Participation in local health cooperative is voluntary

*Partnership and planning to be negotiated through the health board health improvement plans and trust implementation plans. Chairs of trusts will be members of health boards and (with chair of board) jointly accountable to the management executive.

tThe joint investment fund is a new mechanism proposed to manage the interface between primary and secondary care. There remains uncertainty as to how it will operate in practice. It is resource allocation made by the health board from its own central allocation (not new money) made to the primary care trust. It is a means of transferring resources to match changes in clinical practice.

representatives. It has established task groups on prescribing management, clinical governance, and the links between service management and financial management (what budgets should be managed at what level).

Lothian has also been reconfiguring its secondary care services and reviewing which services should be provided by the acute (secondary) or primary care trust. A series of Lothian wide meetings of clinicians were held to discuss key services, including community child health, care of the elderly, rehabilitation, midwifery, and obstetrics. Despite heated debate, the decision for most services was to remain in the acute sector. A senior primary care manager was involved in coordinating the meetings and described the process as retrenchment, suggesting that the decision was explained partly by the pressure of the time scale for decision making, combined with uncertainty about what a primary care trust might look like. Overall, the process has engendered some disquiet about clinical discussion as a basis for development and has left people working in primary care with concerns about influencing and integrating effectively with the acute sector.

\section{Two evolving local healthcare cooperatives}

The two potential cooperatives featured in this article, Midlothian and North West (table), were previously localities.

\section{Midlothian}

"We're doing it because as realists and pragmatists it needs doing ... you can't stick your head in the sand." Marion Storrie, medical director designate
Midlothian is predominantly rural. It has two hospitals providing non-acute geriatric, psychogeriatric, and general psychiatric care. A community hospital is planned which will provide imaging facilities, outpatient clinics, and some inpatient beds.

Midlothian has a history of successful cooperation among general practices. In the early 1990s the locality developed a general practice cooperative for out of hours care which emerged as a leading model. Both the planning process and its success generated a move to collaborative working which practices were willing to build on.

Another uniting factor was that all the practices were politically opposed to fundholding. The development of a PCPI (primary care purchasing initiative) consortium was a "leap of faith" which had only been taken because everyone could see that efficiency savings could be invested in patient care. The consortium has invested in getting pharmacists to support practices and is developing a shared morbidity register. Having the consortium meant that the locality was well resourced to support the work involved in developing a local healthcare cooperative.

Midlothian local healthcare cooperative has agreed a management structure that will support designated care programmes in primary care, mental health, care of older people, and care of mothers and children. As a lead general practitioner explained, "Instead of just having specialties or concentrating on what was within the primary care trust, we looked at how we worked, what we do, and the things that exercise us most." Each of the care programme groups have identified initial priorities (box). However, one general practitioner outside the management team expressed concerns about replacing one unwieldy bureaucratic structure with another.

Care programmes will have some input from social workers, although at present this constitutes liaison or consultation rather than joint planning. The two disciplines have identified shared ground, with both the health sector and the local authority feeling that their resource allocations have not taken rural issues into account. There is, however, a better sense of purpose, particularly in relation to the older people's programme, where cooperative planning could lead to a one stop shop for frail older people.

Despite the history of cooperation and having clear plans, maintaining voluntary participation in local healthcare cooperatives remains a fragile motivational task. The medical director designate explained that "general practitioners will walk out" if local healthcare cooperatives are seen as a means of implementing trust policy rather than being self directed. All general practitioners we spoke to emphasised the need for autonomy and expressed concerns over prescribing budgets and resources. One general practitioner in Midlothian said "the notion is a positive one-getting people to cooperate makes sense but there is an overall lack of strategy and resources-prescribing could wreck the system."

\section{North West}

"Designed to Care? It has potential, but it's still kind of a virtual reality, isn't it?" Shiona Mackie, elected lead general practitioner

North West is the largest of the former localities which divided the city of Edinburgh into quadrants. All city 
local healthcare cooperatives have struggled with the sense of arbitrariness of their boundaries and of trying to develop a shared local identity. The hospitals within the city which will be part of the primary care trust serve the whole city, making management by any one of the local healthcare cooperatives unfeasible.

The North West is socioeconomically and politically diverse (see table). More than half of all patients for whom practices receive a deprivation allowance are registered with just two practices. The locality has a political history characterised by difference rather than unity. The general practitioner leader explained that she's had six years of trying to keep fundholders and non-fundholders together.

Despite this diversity, North West had already established a portfolio of development projects, including one for establishing local mental health teams. The area had also prepared proposals to be a total purchasing consortium.

At present three practices (covering 22\% of the population) do not want to be part of a cooperative. Several others are on the fence or waiting to see. As a lead general practitioner explained, some of the practices seem to feel that they're doing fine as they are, and that they have the opportunity to make and therefore to keep savings. General practitioners working in areas of high deprivation are worried about shared budgets and are concerned that their greater need will be seen as a drain on resources. But one general practitioner from one of the high deprivation practices explained that, despite these background issues and diverging interests, "I don't think there's any doubt that it will happen, it will come together. It's not that we're not capable or not willing to work together, it's just that people can't see the way forward. They just don't see the point, what the offer is."

Although there are enough interested practices to form a local healthcare cooperative, the lead general practitioners are working towards keeping the locality together in what they have designated an alliance on the grounds that cooperatives only make any sense if everybody is involved. The alliance has been meeting every six weeks. These meetings have been well attended by representatives from practices, including those wishing to opt out of the cooperative. They focus on clinical issues, particularly on quality of care and prescribing.

Alongside these meetings an extended project group with representatives from pharmacy, learning disabilities services, mental health services, and nursing has been meeting with the local healthcare cooperative development team to develop a business plan. This extended project group is currently merging with the locality division of Edinburgh Health Care Trust as

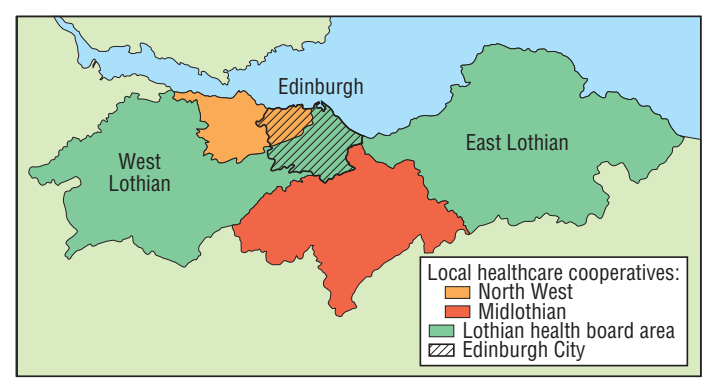

\section{Priorities in Midlothian local healthcare cooperative}

Primary care programme:

- Prescribing management

- Communication and team development tailored to the needs of each primary healthcare team

- Developing a vision for working with professions allied to medicine

- Clinical governance: developing the approach already in place for community nursing and mental health into a performance management framework for the whole of primary care

Mental health:

- Communication between primary and secondary care clinicians

- Developing a joint formulary for psychiatric medication

- Reviewing service provision for adolescents with mental health problems

Older people:

- Liaison with social work

- Discharge planning

Mothers' and children's services:

- Influencing the shape of provision of community midwifery and outreach obstetrics

- Developing a profile of current practice among health visitors and paediatric professions allied to medicine

part of the formation of the primary care trust and is revising its plans and structures. Currently the preferred structure is based on care programmes, with a representative from each care programme being on the management board of the local healthcare cooperative.

The North West area seems to be struggling with the very nature of what constitutes a cooperative, taking the view that "as long as we can come up with the goods [in terms of quality and living within resources] we don't have to call ourselves a local healthcare cooperative."

\section{Conclusion}

This paper tries to encapsulate developments in the past year in Lothian, considering two local healthcare cooperatives to illustrate the processes that are under way. One of the potential cooperatives has developed a structure of a management organisation with extensive interpractice collaboration, and the other seems to be evolving into a form of clinical network.

Several fundamental areas of uncertainty and doubt remain. How will local healthcare cooperatives and the primary care trust engage effectively with the acute sector? Can clinical debate, planning, and partnership form the basis for effective management and change? Is the investment of professional time in local healthcare cooperatives sustainable and cost effective in terms of health gain? Finally, the most important question is: where is patient care in all this? The process of change has meant that as much professional time and effort has been expended on trying to understand and develop new organisational roles and structures as on developing patient care; the time when local healthcare cooperatives can focus all their efforts on the health needs of their populations and developing services to meet those needs is eagerly awaited by all.

1 Secretary of State for Scotland. Designed to care: renewing the National Health Service in Scotland. Edinburgh: Stationery Office, 1997. 